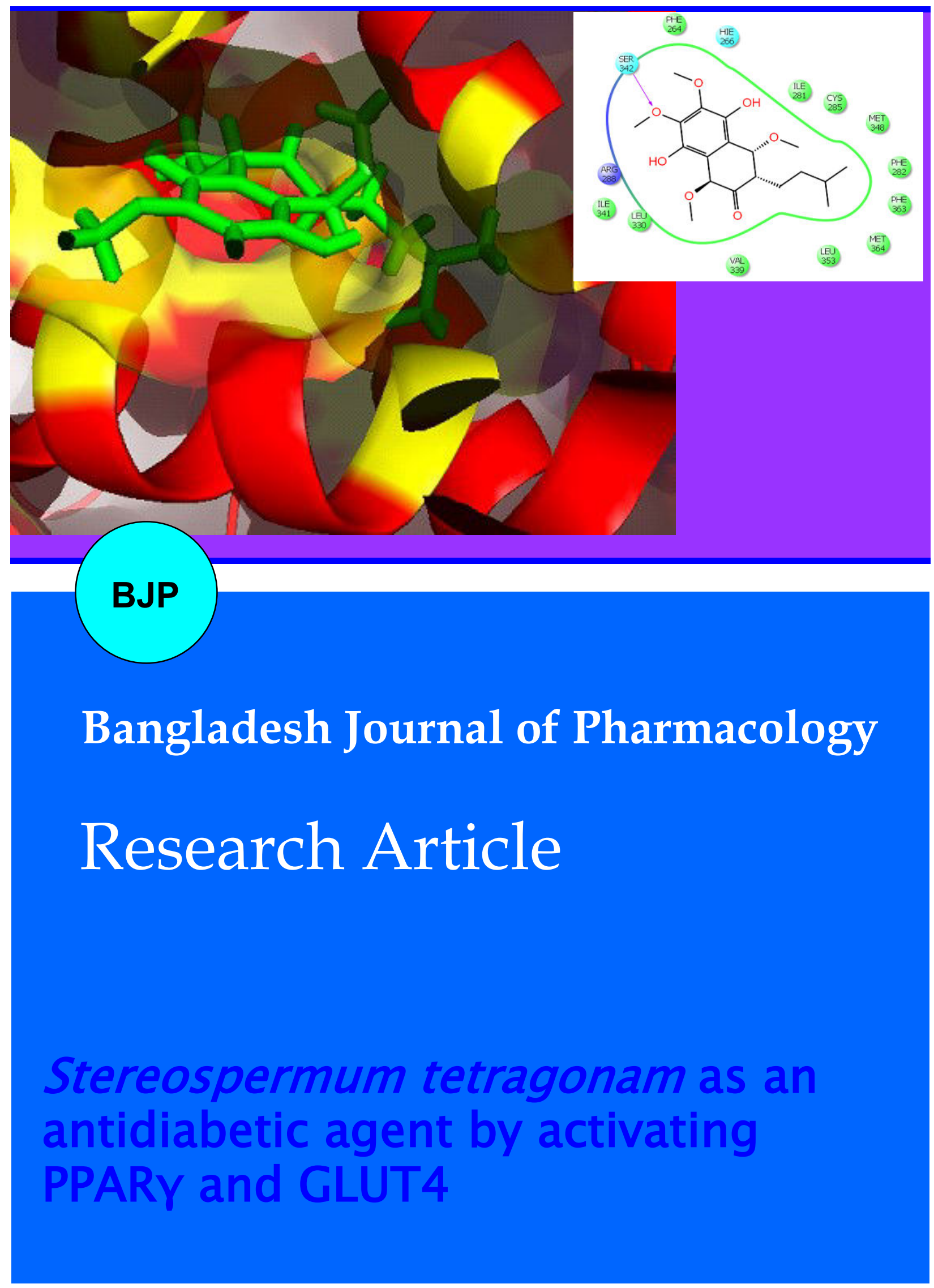




\title{
Stereospermum tetragonam as an antidiabetic agent by activating PPARY and GLUT4
}

\author{
Bino Kingsley,1,2, Arun K. P.1,2, Stalin Selvaraj1,3 and Brindha Pemiah1,2 \\ ${ }^{1}$ School of Chemical \& Biotechnology, SASTRA University, Thanjavur 613 401, Tamil Nadu, India; ${ }^{2}$ Centre for \\ Advanced Research in Indian system of Medicine (CARISM), SASTRA University, Thanjavur 613 401, Tamil Nadu, \\ India; ${ }^{3}$ Centre for Nanotechnology \& Advanced Biomaterials, SASTRA University, Thanjavur 613 401, Tamil Nadu, \\ India.
}

\begin{tabular}{|c|}
\hline Article Info \\
\hline 4 April 2014 \\
\hline 17 May 2014 \\
\hline Available Online: \\
\hline DOI: 10.3329/bjp.v9i2.18488 \\
\hline $\begin{array}{l}\text { Cite this article: } \\
\text { Kingsley B, Arun KP, Selvaraj S, } \\
\text { Pemiah B. Stereospermum tetragonam } \\
\text { as an antidiabetic agent by activating } \\
\text { PPARY and GLUT4. Bangladesh J } \\
\text { Pharmacol. 2014; 9: 250-56. }\end{array}$ \\
\hline
\end{tabular}

\begin{abstract}
Present study evaluates the anti-diabetic activity of $S$. tetragonam LC-MSMS experiments showed the presence of two novel molecules $\mathrm{C} 1$ and $\mathrm{C} 2$, which were further taken for in silico study against PPARy. Cell culture studies with A431 cells in the presence of crude aqueous extract showed the elevated level of PPARY and GLUT4 and also confirmed using in silico studies. Thus, the present study proves the mecode of action of $S$. tetragonam as an antidiabetic drug.
\end{abstract}

\section{Introduction}

Diabetes mellitus (DM) is a major health problem and one of the common endocrine metabolic disorders throughout the world which has caused morbidity and mortality due to microvascular and macrovascular complications. Metabolic disorder of DM arises due to relative or absolute deficiency of insulin secretion (Ozkol et al., 2013). Glucose transporters (GLUT) are the transmembrane proteins responsible for the transport of glucose and other substrates into the cells on the basis of specific inducers (Thorens, 2001). GLUT4 is one of the most important isoforms of GLUT in skeletal muscles and adipocytes, which facilitates the entry of glucose to these hexose utilizing cells (Wood and Trayhurn, 2003). Peroxisome proliferator-activated receptor (PPAR) is a member of nuclear receptor super-family present in adipocytes, muscle and liver. PPAR $\gamma$ triggers cellular assimilation of lipids through anabolic pathways (Semple et al., 2006). The agents like glitazoneclass antidiabetic agents act on PPAR $\gamma$. PPAR $\gamma$ is highly expressed in adipocytes to facilitate glucose and lipid uptake and in turn stimulates glucose oxidation, decreases free fatty acid level and ameliorates insulin resistance in type $2 \mathrm{DM}$.

Recent studies on Stereospermum tetragonum showed promising antidiabetic activity in alloxan- and streptozotocin-induced diabetic model. Two active principles were isolated and identified as an iridoid type glycoside and the other one was a lapachol like compound (Bino Kingsley et al., 2013). The aim of the present study is to determine the active principles and evaluate their efficiency to activate of PPARY and GLUT4 against diabetes mellitus.

\section{Materials and Methods \\ Aqueous extraction of dry powder}

To prepare water extract, the powder $S$. tetragonam was extracted with distilled water $(5 \mathrm{~g} / 100 \mathrm{~mL})$ by stirring for 4 hours and then filtering through filter paper (Whatman No. 1). This process was repeated thrice with 
the residue. The combined filtrate was freeze-dried in a lyophilizer.

\section{Isolation of an active fraction (AF)}

The water extract of $S$. tetragonum root powder was precipitated with absolute ethanol (1:1 v/v) and separated in to precipitate and soluble fractions. Then the soluble fraction of the root extract further purified for the isolation of active principles using thin layer chromatography and characterized using FT-IR and NMR which was already published from our group.

Qualitative analysis of components using electro spray ionization mass spectrometry (ESI-MS/MS)

Qualitative identification of compound C1 and C2 present in the active fraction of $S$. tetragonam, crude aqueous extract of $S$. tetragonam was analyzed using UHPLC/ESI attached to a Q-TOF mass detector (micrOTOF-Q II, Bruker, Germany). First phytomolecules were separated using RP C18 column $(150 \times$ $2.1 \mathrm{~mm}$ with internal diameter of $3.0 \mu \mathrm{m} 120 \AA$ Acclaim ${ }^{\circledR}$, USA). For better elution gradient solvent system was performed using acetonitrile (A) and milliQ water $(1 \%$ acetic acid) starting at $0.2 \mathrm{~min}$ at $1 \% \mathrm{ACN}$ and $99 \%$ water (1\% acetic acid) to $75 \% \mathrm{ACN}$ at 16 th min, this was brought to $100 \% \mathrm{ACN}$ at 19 th $\min$ to $5 \%$ $\mathrm{ACN}$ at 21st min and was maintained at same condition till run ends at $23 \mathrm{rd} \mathrm{min}$, with flow rate of $200 \mu \mathrm{L} / \mathrm{min}$. UV absorbance was detected at arbitrary at $325 \mathrm{~nm}$. Negative mode of ionization was selected at following parameters: Nebulizer 30.5 psi with $6.0 \mathrm{l} / \mathrm{min}$ N2 flow, $\mathrm{m} / \mathrm{z}$ range: $50-1000 \mathrm{~m} / \mathrm{z}$, Capillary voltage $4500 \mathrm{~V}$, dry heater temperature at $280^{\circ} \mathrm{C}$. and analyzed using Data analysis software provided by the manufacturer. Based on the MS and its corresponding MSMS fragmentation pattern, $\mathrm{C} 1$ and $\mathrm{C} 2$ were identified.

\section{Molecular docking}

The structures considered for the study were obtained from the isolation of active fraction and from spectral studies. 1,4a,5,7a-tetrahydro-5-hydroxy-7(hydroxymethyl)-1-(tetrahydro-6-(hydroxy-methyl)3,4,5-trimethoxy-2H-pyran-2-yloxy)cyclopenta [c]pyran -4-carboxylic acid (C1) and 5,8-dihydro-7-isopentyl2,3,5,8-tetramethoxynaphthalene-1,4,6-triol (C2) were used as ligands and draw the structures using CHEMDRAW (Version 11). The structure of PPARY was obtained from the protein databank. Hydrogen atoms were added to the protein consistent with $\mathrm{pH} 7.0$ using the protein preparation wizard in the Schrödinger suite (Madhavi Sastry et al., 2013). Further, the protein's hydrogen bond network was also optimized using the wizard. The so-prepared structure was then subject to energy minimization and the termination condition for minimization was fixed as the step when the root mean square deviation of the heavy atoms in the structure relative to the starting structure exceeded $0.3 \AA$. This process also ensures that the hydrogen atoms are placed in optimized geometries. The protein thus prepared was used for docking of the ligands as described below. Potential binding sites in PPARY were predicted using the SiteMap tool in the Schrödinger suite (Halgren, 2007; Halgren, 2009). Five different binding sites were identified in PPAR. Of these predicted sites, site 3 had the highest score. Hence binding of a ligand to site 3 is more likely to result in the activation of this receptor. Receptor grid was then generated for site 3 using Glide module (v 5.8) of the Schrödinger suite. The grid box and center were set to default. LigPrep module (version 2.5) of the Schrödinger suite was used to generate conformers of the ligands. The ligands were then docked using the extra precision mode in the Glide module (Friesner et al. 2004; Friesner et al., 2006; Halgren et al., 2004) of the Schrödinger suite.

\section{Cell culture assay}

A431 human skin carcinoma cells (NCCS, INDIA) were maintained in Dulbecco's Modi-fied Eagle Medium (DMEM) containing high glucose level of $4.5 \mathrm{~g} / \mathrm{L}$, Lglutamine, sodium pyruvate and sodium bicarbonate. $20 \%$ Fetal calf serum (FCS) and 1\% pen-strep antibiotics were added in the working media solution. A431 cells line are well known for their expression study on GLUT4 and PPAR gamma.

\section{Determination of cell GLUT4 and PPAR gamma}

Cell lysate were made and the resultant supernatant was used for the estimation of GLUT4 and PPAR gamma expression levels using ELISA kit (Qiagen QY03235). Briefly, at $70 \%$ confluence, cells were trypsinized and $0.2 \times 10^{6}$ cells were seeded and grown to $70 \%$ confluence in a 24 -well tissue culture plate conditioned with $5 \% \quad \mathrm{CO}_{2}$ atmosphere at $37^{\circ} \mathrm{C}$. Cells were then treated with 20,30 and $40 \mu \mathrm{g} / \mathrm{mL}$ of active fraction of $S$. tetragonam for 48 hours followed by cell lysis using tween 80, resulted mixture was then mixed and centrifuged for $10 \mathrm{~min}$ at 3,000 rpm. Supernatant was collected and used as test sample for ELISA. Assay was performed by the addition of test samples at different concentration into respective wells which are already coated with anti-GLUT4 and anti-PPAR gamma antibodies, followed by the addition of secondary antibody conjugated to horse-radish peroxidase except for the blank wells; this was then incubated for $60 \mathrm{~min}$ at $37^{\circ} \mathrm{C}$. Each wells were then washed thrice with $1 \times$ PBS (washing buffer), followed by the addition of chromogen solution (o-phenylene-diamine dihydrochloride) with gentle shake and incubated at dark condition for $10 \mathrm{~min}$ at room temperature. This reaction was terminated with the addition of $3 \mathrm{~N} \mathrm{HCl}$ (stop solution). Absorbance were read at $450 \mathrm{~nm}$ using Microplate Reader (Epoch, BioTek, USA) within 15 min 


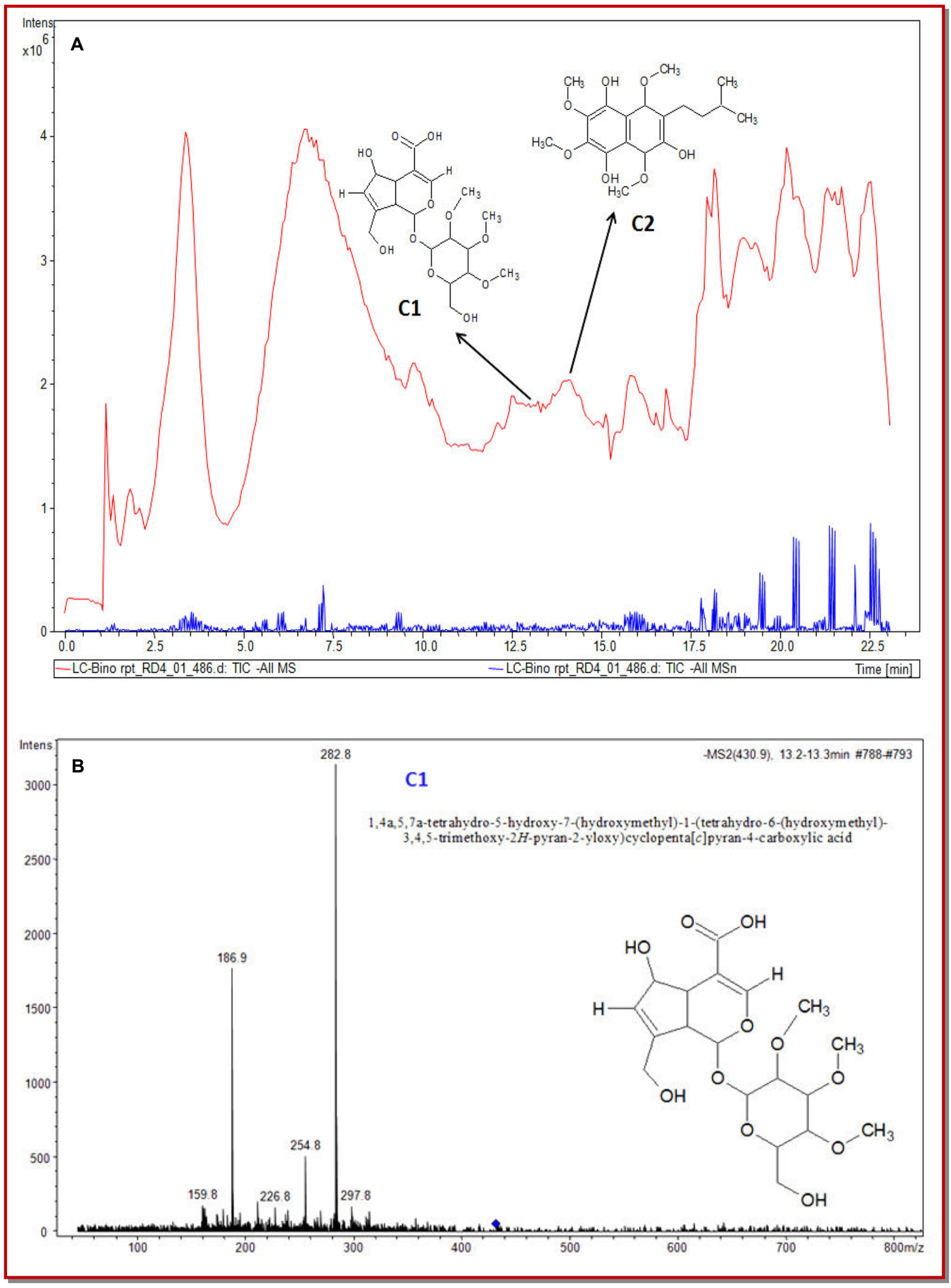

Figure 1: LC/MS/MS pattern for novel two active principles present in the aqueous extract of S. tetragonam 


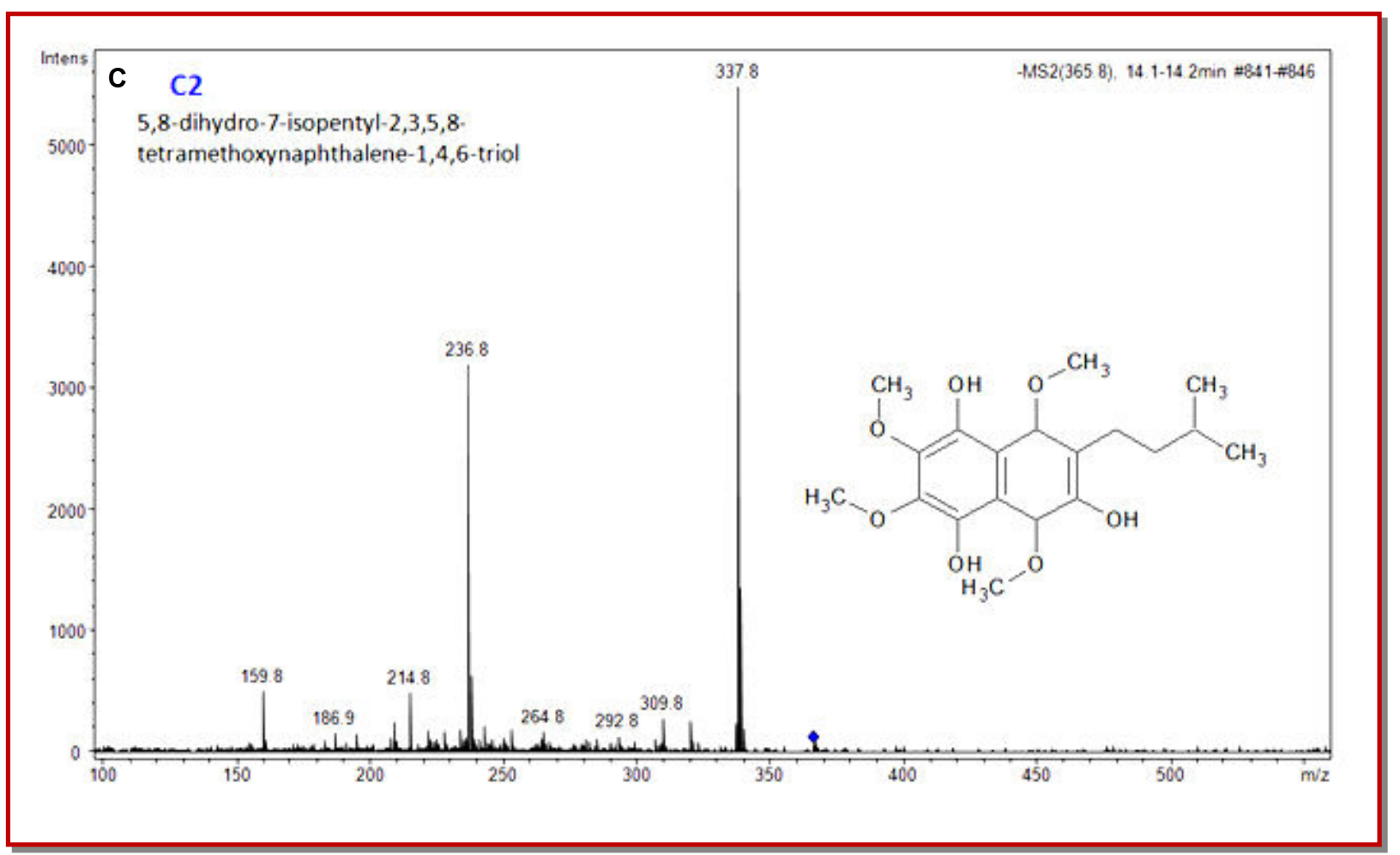

Figure 1: LC/MS/MS pattern for novel two active principles present in the aqueous extract of S. tetragonam (Continued)

after reaction termination. Background absorbance obtained with blank well was subtracted from all values of other wells. Estimation of GLUT4 and PPAR gamma in the test samples were determined according to standard graph generated using various standard concentrations and their corresponding OD values.

\section{Results and Discussion}

$\mathrm{C} 1$ and $\mathrm{C} 2$ were identified using LC-MSMS analysis on the active fraction of $S$. tetragonam. $\mathrm{C} 1$ has shown a $\mathrm{m} / \mathrm{z}$ value of 431 [M-H]- with major MS2 peaks as 283, 187, $255,298,255,160,227,269$. Similarly C2 showed m/z value of $366[\mathrm{M}-2 \mathrm{H}]^{-}$with major MS2 peaks were 338, $237,160,215,310,265,293,187$. MSMS fragmentation pattern of $\mathrm{C} 1$ and $\mathrm{C} 2$ proves the proposed structure of these molecules (Figure 1).

Active fraction has shown its antidiabetic activity by elevating the expression level of PPAR gamma and GLUT4 as seen through ELISA detection of these proteins in the A431 treated cell lysate (Figure 2). PPAR gamma activation is essential for the gene level activation of glucose uptake related proteins specifically GLUT4 transporter. Increase level of PPAR gamma leads to the increase expression level of GLUT4 in the cell membranes which in turn increase the uptake of blood glucose and utilizes it within the cell as energy metabolism or for storing it as glycogen for further usage. Many synthetic drugs have shown binding affinity followed by activation of peroxisome proliferator-activated receptor (PPAR-gamma) (Marx and Hombach, 2001; McCarthy and Elmendorf, 2007). PPAR related proteins are well known for its role in lipid homeostasis through fatty acid catabolism and are present at high levels in the adipose tissues, liver and in skin epithelial cells. Specifically PPAR-gamma is highly expressed in adipose tissues during adipogenesis. Although binding of ligands to PPAR gamma is required for its transcriptional activation, natural occurring ligands against PPAR proteins are not yet scientifically explored which can be used as an ecofriendly antidiabetic drug. Present study has clearly demonstrated that $\mathrm{C} 1$ and $\mathrm{C} 2$ require minimum binding energy to bind with PPAR-gamma. Present studies provide scientific evidence that $\mathrm{C} 1$ and $\mathrm{C} 2$ are involved in the activation of PPAR-gamma which in turn provides antidiabetic activity through activation of GLUT4 (Semple et al., 2006; Thorens, 2001).

The activation of PPARY is further confirmed using in silico studies. It indicates that both $\mathrm{C} 1$ and $\mathrm{C} 2$ strongly interact with PPARY through different residues (Figure 3 and 4). Among the two C1 exhibited maximum number of hydrophobic interactions compared to $\mathrm{C} 2$. The XP Glide score for both the compounds includes $4.7 \mathrm{Kcal} / \mathrm{mol}$ for $\mathrm{C} 1$ and $-4.0 \mathrm{Kcal} / \mathrm{mol}$ for C2 clearly suggested that both the compounds show better interaction with PPARY which may probably activate PPARY signaling cascades thereby increasing the levels of GLUT4. This is already confirmed through ELISA experiments. 


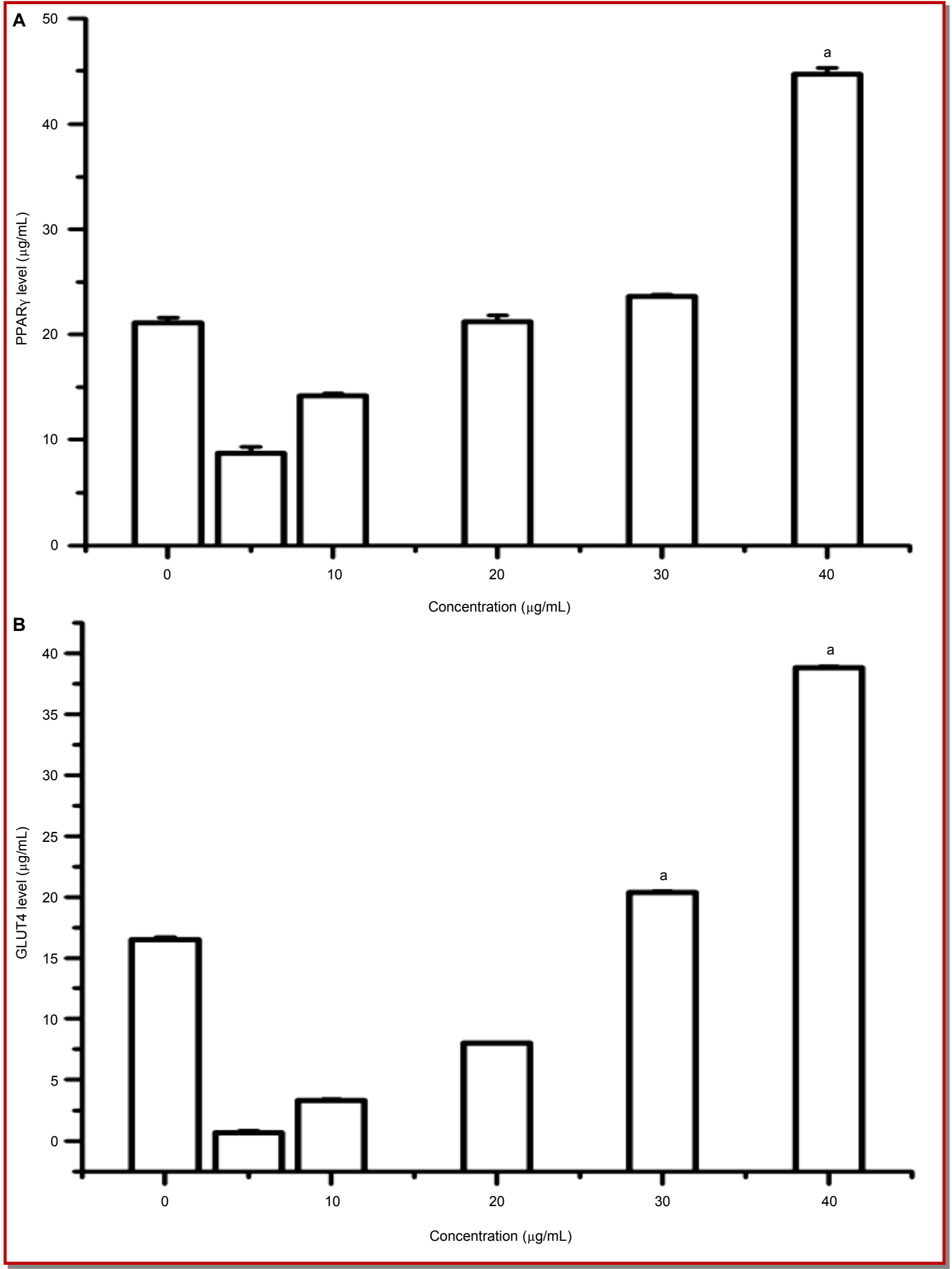

Figure 2: Influence of different concentrations aqueous extract of $S$. tetragonam on the activity of PPARY (A) and GLUT4 (B). Values are expressed as mean $\pm S D ; n=4$; ${ }^{a} p<0.05$ 


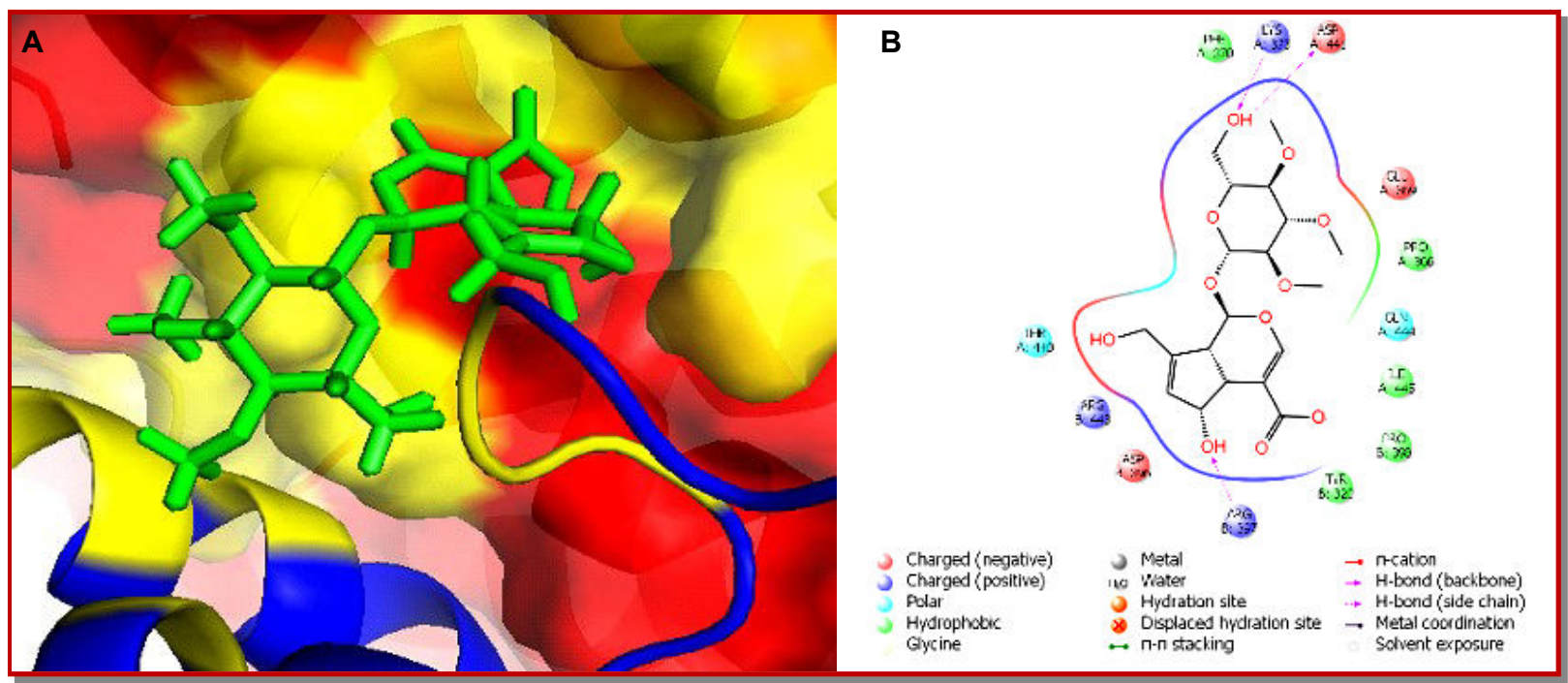

Figure 3: Probable interaction of C1 with PPARY predicted using molecular docking studies. A: surface view; B: ligand interaction diagram

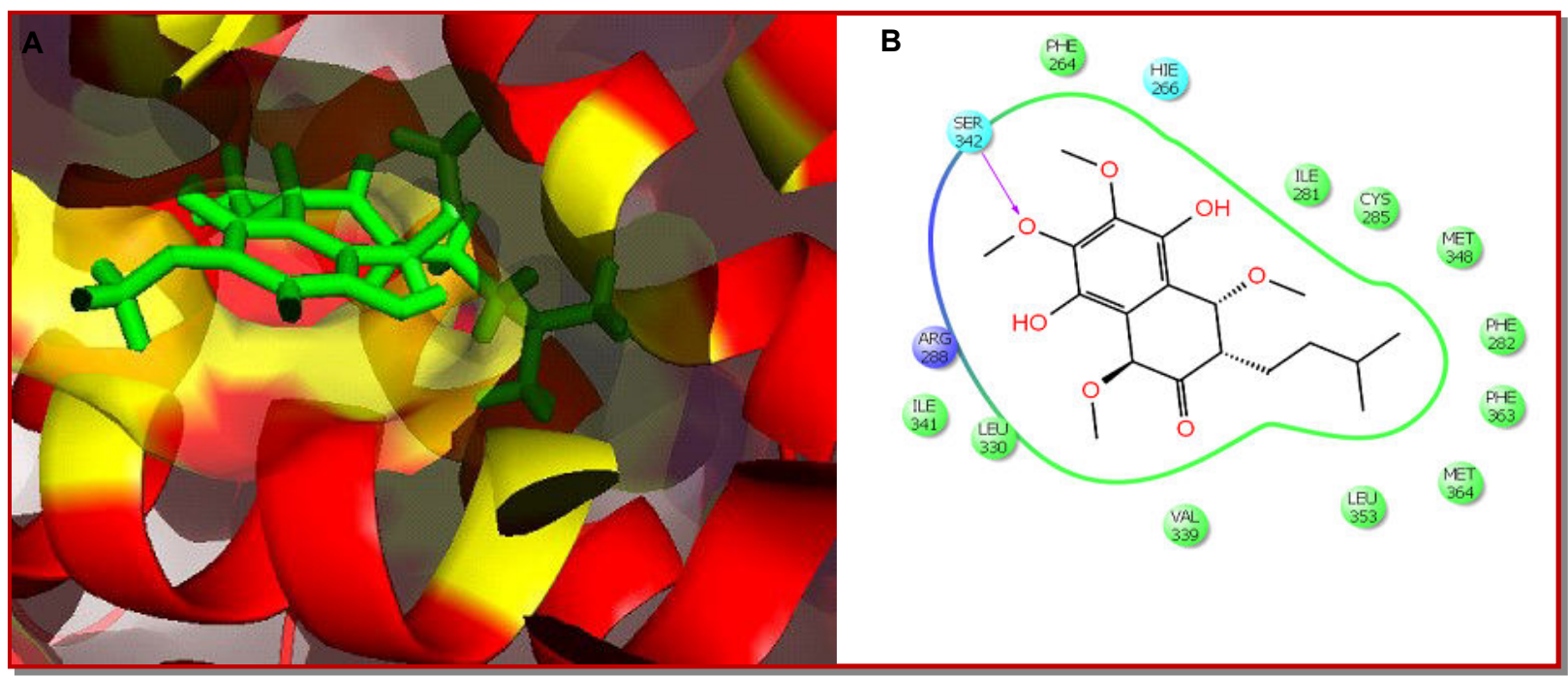

Figure 4: Interaction of C2 compound with PPARY predicted using in silico studies. A: Surface view; B: Ligand interaction diagram

The present study evaluated the molecular mechanism for the antidiabetic potential of Indian herb, S. tetragonam using ELISA technique and molecular docking. LC/MS/MS technique results indicated that the aqueous extract of $S$. tetragonam contains two new compounds (C1 and C2). The cell culture studies indicated that the extract dose dependently increase the level of PPARY and GLUT4 compared to control which in turn express the levels of thereby increasing glucose metabolism.

\section{Acknowledgements}

The authors wish to acknowledge SASTRA University for financial and infrastructural support.

\section{Contribution}

First two authors contributed equally in this study.

\section{References}

Bino Kingsley R, Mishra M, Brindha P, Subramoniam A. Antidiabetic activity of active fractions of Stereospermum tetragonum DC. and isolation of active principles. J Young Pharm. 2013; 5: 7-12.

Friesner RA, Banks JL, Murphy RB, Halgren TA, Klicic JJ, Mainz DT, Repasky MP, Knoll EH, Shelley M, Perry JK, Shaw DE, Francis P, Shenkin PS. Glide: A new approach for rapid, accurate docking and scoring. 1. Method and assessment of docking accuracy. J Med Chem. 2004; 47: 1739 -49 . 
Friesner RA, Murphy RB, Repasky MP, Frye LL, Greenwood JR, Halgren TA, Sanschagrin PC, Mainz DT. Extra precision Glide: Docking and scoring incorporating a model of hydrophobic enclosure for protein-ligand complexes. J Med Chem. 2006; 49: 6177-96.

Halgren T. New method for fast and accurate binding-site identification and analysis. Chem Biol Drug Design. 2007; 69: 146-48.

Halgren TA. Identifying and characterizing binding sites and assessing druggability. J Chem Inf Model. 2009; 49: 377-89.

Halgren TA, Murphy RB, Friesner RA, Beard HS, Frye LL, Pollard WT, Banks JL. Glide: A new approach for rapid, accurate docking and scoring. 2. Enrichment factors in database screening. J Med Chem. 2004; 47: 1750-59.

Madhavi Sastry G, Adzhigirey M, Day T, Annabhimoju R, Sherman W. Protein and ligand preparation: Parameters, protocols, and influence on virtual screening enrichments. J
Comput Aided Mol Des. 2013; 27: 221-34.

Ozkol H, Tuluce Y, Dilsiz N, Koyuncu İ. Therapeutic potential of some plant extracts used in Turkish traditional medicine on streptozocin-induced type 1 diabetes mellitus in rats. J Membrane Biol. 2013; 246: 47-55.

Postic C, Shiota M, Magnuson MA. Cell-specific roles of glucokinase in glucose homeostasis. Recent Prog Horm Res. 2001; 56: 195-217.

Semple RK, Chatterjee VK, O'Rahilly S. PPAR gamma and human metabolic disease. J Clin Invest. 2006; 116: 581-89.

Thorens H-GJB. The extended GLUT-family of sugar/polyol transport facilitators: Nomenclature, sequence characteristics, and potential function of its novel members. Molec Membrane Biol. 2001; 18: 247-56.

Wood IS, Trayhurn P. Glucose transporters (GLUT and SGLT): expanded families of sugar transport proteins. Bri J Nutri. 2003; 89: 3-9. 